\title{
Identification of suitable reference genes for gene expression normalization in Jatropha curcas $L$ during development and under stress conditions using Real Time Quantitative PCR
}

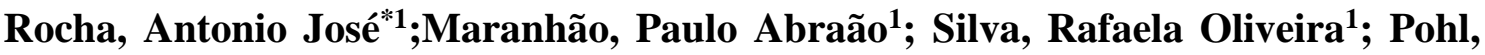 \\ Simone $^{2}$; Fonteles, Cristiane S.R $\mathbf{R}^{3}$ \\ ${ }^{1}$ Federal University of Ceará - Department of Biochemistry and Molecular Biology; Fortaleza, Ceara, \\ Brazil, ${ }^{2}$ Federal University of Pelotas - UFPel - Department of Plant Science; Fortaleza, Ceara, Brazil, ${ }^{3}$ Federal \\ University of Ceará - Department of Clinical Dentistry; Fortaleza, Ceara, Brazil.
}

\begin{abstract}
Jatropha curcas L represent a potential source of raw material for the production of biodiesel. The aim this study was to find potential candidate reference genes in J. curcas tissues. Three softwares were utilized to verify which would be the most stable reference genes in qPCR assay: GeNorm, NormFinder and BestKeeper. The most stable reference genes in developing J. curcas seeds suggested by GeNorm were GAPDH, UCP, actin. However, the best combinations of stable genes in each tissue were identified separately under stress conditions: EF1- $\alpha$, $P P 2 A 2$ and GAPDH in total stress, however, in SA stress, four genes were required for normalization: PP2A2, EF1- $\alpha$, GAPDH and PUB. In PEG stress, four genes also were required: PP2A2, EF1- $\alpha$, GAPDH and PUB, while in NaCl stress, five genes were necessary: PP2A2, GAPDH, EF1- $\alpha, P U B$ and TB2. These results are in accordance with two other programs used in this study (NormFinder, BestKeeper). In addition, the transcript levels of JC-SRG-2 seem to be more correlated with stress responses than changes in transcript levels of Jc-SRG1, mainly of leaves in exposure to 3-12h on PEG and NaCl stress. Taken together, GAPDH and PP2A2 were regarded as being the best reference to provide guidelines for the selection of potential references genes under these study conditions.
\end{abstract}

Keywords: Gene expression,RT-qPCR, Reference genes, Jatropha curcas L

\section{INTRODUCTION}

Jatropha curcas (L.) seeds are a potential source of raw material for the production of biodiesel.However, the use ofJatropha curcas (L.) seedsfor this purpose has been hampered by the lack of basic knowledge regarding certain aspects of the biochemistry of these seeds. For instance, details about the enzymatic pathways of the biosynthesis of lipids and of toxic phorbol esters (PE), as well as, related genes when these seeds are exposed to different types of stress (Rocha et al. 2013). Recent release of the complete nuclear and chloroplast genomes (Sato et al. 2011; Asif et al. 2010) of this species, as well

\footnotetext{
*Author for correspondence: antonionubis@gmail.com
} 
Rocha, AJ et al.

as the publication of several studies on the transcriptome of seed tissues (Natarajan et al. 2010; Costa et al. 2010; Natarajan et al. 2011).This provides information on the search of new genes with important contribution regarding the metabolism of this plant, that will certainly improve our understanding of the metabolic pathways underlying the developmental processes related to oil metabolism and of the biosynthesis of toxic and/or allergenic compounds (Soares et al.2014; Shah et al. 2015) qPCR is thought to be the appropriate approach to study the expression patterns of the relevant genes involved in these processes due to its accuracy, sensitivity and reproducibility (Rocha et al. 2015). RNA quality, cDNA synthesis and stable reference genes are important factors to be considered in reverse transcription followed by qPCR experiments, because they account for the experimental variation that can occur during the process of amplification(Vandesopele et al. 2002; Rocha et al. 2015).

To our knowledge only 2 previous studies have focused on evaluating the normalisation of qPCR using reference genes present in the biofuel plant Jatropha curcas. Rocha et al (2013) were the first to identify and evaluate potential reference genes for expression studies in J. curcas for qPCR analyses, but the authors restricted their experiments to the use of developing seeds, used only six reference genes, did not include stress condition analysis, and applied only GeNorm software to normalize the data. Recently, Zhang et al (2013) published a gene expression study using reference genes in Jatropha in different tissues throughout development and only 2 under stress conditions (desiccation and cold stress treatments). The authors examined a total of 11 typical candidate reference genes using qPCR analysis, which were used for validating transcript levels in gene expression studies. The authors used 2 target genes: JcRD29b and Jc DREB1A The expression stability of these candidate reference genes was assessed across a total of 20 samples. However, Zhang et al. (2013) restricted their study to only 2 stress conditions (desiccation and cold treatments). Thus, our study consists on a better study on normalization using reference genes present in Jatropha curcas, making the present work more meticulous and complete in comparison to the two studies previous studies (Rocha et al. 2013 and Zhang et al. 2013).

Since qPCR results are highly dependent on the choice of appropriate reference gene(s) to control for experimental error, ideally these have to display only minor differences in their expression profile under various developmental conditions or tissue types. Reference genesare commonly investigated as internal controls for normalization in gene expression analyses, but there are evidences that the most widely used reference genes are not reliable controls, due to variations in their transcript levelsin different tissues (Paolacci et al. 2011, Rocha et al. 2015).Hence, the present study aimed to assess the stability of actin (ACTIN), tubulin alpha-2 (T $\alpha 2)$, tubulin beta (T $\beta 2)$, elongation factor 1-alpha $(E F 1-\alpha)$, protein phosphatase 2A-2 (PP2A2), polyubiquitin (PUB), ciclofilin, ubiquitin conjugation protein (UCP) and glyceraldehyde-3phosphate dehydrogenase (GAPDH) as reference genes in RNA samples derived from developing seeds and leaves of $J$. curcas seedlings under four stress conditions.

\section{MATERIALS AND METHODS}

\section{Seed harvest and tissue isolation}

Seeds of $J$. curcas were collected from plants grown at the Experimental Farm of the Federal University of Ceará. Female flowers were hand-pollinated and developing seeds were collected at 10-15, 20-25, 30-35 days after pollination (DAP) and maturation according to size and color of the developing seeds (data not shown).The seeds were surface-sterilized in $1 \%$ sodium hypochlorite solution for five min and exhaustively rinsed with distilled water. The sterilized seeds were sown on filter paper imbibed in distilled water and maintained in the greenhouse. After 6 days, the Jatropha curcas seedlings were transferred to a hydroponic system that contained Hoagland's nutritive solution medium $\left(1 \mathrm{M} \mathrm{KNO}_{3}, 1 \mathrm{M} \mathrm{MgSO}_{4}, 1 \mathrm{M} \mathrm{Ca}\right.$ $\left(\mathrm{NO}_{3}\right)_{2}, 1 \mathrm{M} \mathrm{NH} 4 \mathrm{H}_{2} \mathrm{PO}_{4}$ and $0.5 \% \mathrm{Fe}-$ 
Identification of suitable reference genes for gene expression normalization in Jatropha curcas $L$ during development and under stress conditions using Real Time Quantitative PCR

EDTA) with micronutrients (2.86 $\mathrm{g} \mathrm{L}-1$ $\mathrm{H}_{3} \mathrm{BO}_{3}, 1.86$ g L-1 $\mathrm{MnCl}_{2}, 0.22$ g L-1 $\mathrm{ZnSO}_{4}, 0.08 \mathrm{~g} \mathrm{~L}-1 \mathrm{CuSO}_{4} .5 \mathrm{H}_{2} \mathrm{O}$ and 0.20 gL- $1 \mathrm{Na}_{2} \mathrm{MoO}_{4}$ ). To induce stress, seedlings were subjected to treatments with $100 \mathrm{~g} \mathrm{~L}-1$ polyethylene glycol (PEG), $0.5 \mathrm{mM}$ salicylic acid (SA) and $100 \mathrm{mM}$ of sodium chloride $(\mathrm{NaCl})$ applied at 10 DAS. PEG and $\mathrm{NaCl}$ was added to the nutritive solution, and SA was sprayed onto the leaves. For the purpose of this study, the seedlings were also exposure to combinations of three stress (SA, PEG, NaCl) called in this study of total stress. In both treatments, leaves were harvested from at least three plants after0, 3, 6 , and 12 of stress exposure.

All the collected samples were obtained from a pool of 20 seeds and were stored in a freezer at $-80^{\circ} \mathrm{C}$. For RNA extraction, tissue samples were immediately frozen in liquid $\mathrm{N}_{2}$ and then stored at $-80^{\circ} \mathrm{C}$ until further use.

Extraction of total RNA and cDNA synthesis

Initially, approximately $300 \mathrm{mg}$ of fresh material obtained from a pool of 20 seeds were pulverized with liquid Nitrogen and the total RNA was extracted using the Plant RNA Purification Reagent (Invitrogen ${ }^{\circledR}$ ). The same procedure was used on the seedling that underwent stress conditions. In order to improve RNA quality, the samples were subjected to further purification using the RNeasy Plant Mini Kit (Quiagen $®$ ), which included an on-column DNase digestion to eliminate genomic DNA contamination. The concentration of RNA samples was determined using the Nanodrop 2000 spectrophotometer (Thermo Scientific) at $260 \mathrm{~nm}$. Absorbance ratios at 260/280 and $260 / 230 \mathrm{~nm}$ were used to assess the purity of total RNA (Sambrook et al.1989; Rocha et al. 2014). To determine the integrity of total RNA, $0.5 \mu \mathrm{g}$ of RNA was analyzed by electrophoresis on $1.2 \%$ agarose gel stained with ethidium bromide $(0.5 \mu \mathrm{g} / \mu \mathrm{L})$.

Synthesis of cDNA was performed using 1 $\mu \mathrm{g}$ of purified total RNA in the reverse transcription reaction. For each reaction, $1 \mu 1$ of Oligo-DT ${ }_{12-18} 0.5 \mu \mathrm{g} / \mu \mathrm{L}$ (Invitrogen ${ }^{\circledR}$ ), 1 $\mu \mathrm{l}$ of dNTP $10 \mathrm{mM}$ (Quiagen $\circledR$ ), $2.4 \mu \mathrm{l}$ of $\mathrm{MgCl}_{2} 25 \mathrm{mM}$ (Invitrogen $®$ ), $4 \mu \mathrm{l}$ of $5 \mathrm{X}$ reaction buffer (ImProm-II TM Reaction Buffer, Promega $\left.{ }^{\circledR}\right)$, autoclaved ultrapure RNase-free water (Milli-Q) and $1 \mu \mathrm{L}$ of reverse transcriptase-II TM (Promega ${ }^{\circledR}$ ) were added to each sample, completing a reaction volume to $20 \mu \mathrm{l}$. The cDNA obtained was stored at $-20^{\circ} \mathrm{C}$ until used.

\section{PCR primer design}

Nine candidate reference genes were selected for qPCR assay: ACT11, T $\alpha 2, \mathrm{~T} \beta 2$, EF1- $\alpha, \quad$ PP2A2, polyubiquitin (PUB),GAPDH, cliclofilin, and UCP. These genes were screened to determine the most stable reference genes to be used in theqPCR normalization, and the corresponding sequences were retrieved from a seed EST database of J. curcas (Costa et al. 2010). The six reference gene sequence primers (actin11 (ACT11), tubulin alpha-2 (T $\alpha 2$ ), elongation factor 1-alpha $(\mathrm{EF} 1-\alpha)$, protein phosphatase 2A-2 (PP2A2), polyubiquitin-3 (PUB3), glyceraldehyde-3-phosphate dehydrogenase (GAPDH) were supplied and published by Rocha et al. 2013. The other three primers (cliclofilin, ubiquitin conjugation protein (UCP) and tubulin beta $-\mathrm{T} \beta 2$ ), as well as the two target genes entitled here as Jc-SRG-1 (Jatropha curcas-StressResponsive Genes) and Jc-SRG-2 were used to validation this work that were obtained from the Jatropha Genome Database (Public databank) available at http://www.kazusa.or.jp/jatropha/. The primers were designed in the exon/exon junction using Perl Primer v1.1.19 software (Marshall, 2004) with melting temperatures $(\mathrm{Tm})$ of $58-60^{\circ} \mathrm{C}$, primers lengths of $20 \mathrm{bp}$ and amplicon lengths of 60 to $210 \mathrm{bp}$ (Table 1). All primer pairs were initially tested via standard RT-PCR and amplification of single products of expected sizes was verified by electrophoresis on $2 \%$ agarose gels and ethidium bromide staining (data not shown).

Table 1- References of primer sequences used for gene expression analysis in $J$. curcas throughout development and under stress conditions.

\section{Real-time quantitative PCR-qPCR}

The qPCR was performed using the Mastercycler ${ }^{\circledR}$ ep realplex (Eppendorf AG, 
Rocha, AJ et al.

Hamburg) in a reaction plate of 96 wells and the assays were conducted as indicated Power SYBR Green PCR Master Mix (Applied Biosystems). Each reaction contained 0.4 ul of each primer (300

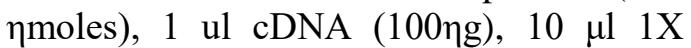
Power SYBR Green PCR Master Mix and and $8.2 \mathrm{uL}$ of ultra pure water in a final volume reaction of $20 \mu \mathrm{l}$. Aliquots of the same cDNA sample were used in all sets of primers in each experiment. qPCR assays were performed in quadruplicate technical. Reactions were run using the following parameters: 10 minutes at $95^{\circ} \mathrm{C}$ for activation of the enzyme, followed by 40 cycles of denaturation at $95{ }^{\circ} \mathrm{C}$ for $15 \mathrm{~s}$, annealing at $55^{\circ} \mathrm{C}$ for $20 \mathrm{~s}$, and extension at $60{ }^{\circ} \mathrm{C}$ for $20 \mathrm{~s}$. After amplification was complete, a melting curve in which fluorescence (F) was plotted against temperature $(T)$, was obtained by holding at $95{ }^{\circ} \mathrm{C}$ for $15 \mathrm{~s}$ and then at $60{ }^{\circ} \mathrm{C}$ for $15 \mathrm{~s}$, followed by heating slowly at $0.2^{\circ} \mathrm{C} / \mathrm{s}$ to 95 ${ }^{\circ} \mathrm{C}$ with continuous collection of fluorescence at $640 \mathrm{~nm}$.

Stability gene analysis

In the present study, three different statistical programs were used to estimate the stability of gene expression: GeNorm software version 3.5 (Vandesompele J et al. 2002), the NormFinder (Andersen et al. 2004) and Bestkeeper (Pfaffl et al. 2004). Transcript levelswere determined as the number of amplification cycles needed to reach a fixed threshold in the exponential phase of the PCR reaction (Ct) (Reid et al. 2006). Raw Ct values were converted to relative quantities using normalisation factor (NF) and imported to genorm ${ }^{\text {PLUS }}$ module in qbase ${ }^{\text {PLUS }}$ software version 1.5(Biogazelle) (Vandesompele et al. 2002). In addition, NormFinder and BestKeeper software (Andersen et al. 2004; Pfaffl et al. 2004; Vandesompele et al. 2002) were used to perform data normalisation. $\mathrm{Ct}$ values were used directly for stability calculations for BestKeeper or were transformed to relative quantities using delta-Ct method by

(GeNorm, NormFinder).

The GeNorm calculates a gene-stability measure $(M)$, defined as an average pairwise variation $(V)$ of a particular gene reported to all other control genes. Genes with the lowest $M$ values have the most stable expression. Usually, $\mathrm{M}$ values $<1.5$ are regarded as acceptable levels of expression stability. Stepwise exclusion of the gene with the highest $M$ value allows ranking of the tested genes according to the stability they express. (Vandesompele J et al. 2002). The GeNorm program also estimate the number of genes that require appropriate controls for normalization, by the evaluation of variation in pairs ( $\mathrm{V}$ values), checking the variation of the expression of every two possible genetic combinations between two consecutively ranked normalization factors (NF). Most recently, Vandesompele modified some rules of geNorm:for homogeneous samples such as from cell cultures of the same cell type, $M$ should be lower than 0.5 and the $\mathrm{CV}$ should be below $25 \%$. In more heterogeneous sample sets (e.g. when comparing different cell types, clinical biopsies, cancer tissue in general, etc.) reference genes are typically more variable; here, we advise to aim for $\mathrm{M}<1$ and $\mathrm{CV}<50 \%$ available at https://www.biogazelle.com/four-tips-rtqpcr-data-normalization-using-referencegenes

The NormFinder is an algorithm for identifying the optimal normalization gene among a set of candidates. It ranks the set of candidate normalization genes according to their expression stability in a given sample set and experimental design. The algorithm is rooted in a mathematical model of gene expression and uses a solid statistical framework to estimate not only the overall expression variation of the candidate normalization genes, but also the variation between sample subgroups of the sample set e.g. normal and cancer samples (Andersen et al. 2004).

BestKeeper algorithms analyze the quantification cycle ("Cq") value to evaluate the expression variability of the reference genes. The BestKeeper is based on the coefficient of correlation (" $r$ ") and standard deviation ("SD") values. The higher the rvalue, the most stable is the gene; however, the lower the SD-value, the most stable is the gene (Liu et al. 2001; Pfaffl et al. 2004). SD is the key factor in the analysis, and the highest SD value of each reference gene indicate less stability. Data with SD $[ \pm \mathrm{Cq}]<$ 1 were considered acceptable ranges of 
Identification of suitable reference genes for gene expression normalization in Jatropha curcas $L$ during development and under stress conditions using Real Time Quantitative PCR

variation. The BestKeeper also calculates a pairwise r-value between each reference gene and a coefficient of variation ("CV") based on the $\mathrm{Cq}$ values (CV [\% Cq]) of all candidate reference genes.

\section{Reference gene validation}

The cDNA samples used in the reference gene analysis were also analyzed by qPCR for the expression of Jc-SRG-1 and Jc-SRG2 ,in order to determine how the adoption of one or multiple genes can affect the normalization of relative expression data, thus validating our experiments. The JcSRG-1 and Jc-SRG-2 expression data were normalized using the three most stable reference genes indicated by GeNorm and their geometric average approaches.

\section{Data analyses}

The analysis of relative expression was carried out by normalisation factor and the calculation of normalized relative transcript levelswas done using the qbase ${ }^{\text {PLUS }}$ software version 1.5(Biogazelle) (Vandesompele et al. 2002). Nine candidate genes were tested (ACT11, PUB, GAPDH, PP2A2, EF1- $\alpha$, $\beta$ tubulin, $\alpha$-tubulin, UCP and ciclofilin) and validated using using profile gene expression of Jc-SRG-1 and Jc-SRG-2 from the genorm $^{\text {PLUS }}$ module in qbase ${ }^{\text {PLUS }}$.
All qPCR reactions were performed in quadruplicate and $\mathrm{Ct}$ values were averaged.Primer efficiency was determined by the dilution method employed, in which $\mathrm{E}(\%)=\left(10^{(-1 / \text { sloop })}-1\right) \times 100$ approach, in which the sloop with $-3,33$ value is regarded ideal cycles. Besides, was carried out a temperature gradient reaction from 50 to $65^{\circ} \mathrm{C}$ to estabilish the anelament temperature of primers studies. Reaction products were analyzed by melting curves in order to verify the absence of unspecific products and/or primer/dimer formation.

\section{RESULTS}

\section{Specificity of Primers for PCR}

Selected transcript levels of the nine candidate genes (Table 1) were measured by qPCR using 9 gene-specific primer pairs to examine the expression stability of potential reference genes. Absence of primer-dimer and non-specific amplification is especially important when qPCR is carried out using SYBR green.

Table 1- References of primer sequences used for gene expression analysis in J. curcas throughout 
Rocha, AJ et al.

Gene-specific amplification of each of the nine candidate genes was confirmed by the
Ct values) was used to estimate the level of transcription of each reference gene tested

\begin{tabular}{|c|c|c|c|c|}
\hline GENE & $\begin{array}{l}\text { ACCESS CODE } \\
\text { (GENBANK) }\end{array}$ & PRIMERS SEQUENCES (5' - 3') & $\begin{array}{l}\text { AMPLICON } \\
\text { (PB) }\end{array}$ & $\begin{array}{l}\text { PRIMERS } \\
\text { EFFICIENCY } \\
(\%)\end{array}$ \\
\hline ACT11 & JGCCJG2058B09.b & $\begin{array}{l}\text { CTAAAGGCTAATGGGGAAAC/ } \\
\text { CAACCACTTGATTAGAAGCC }\end{array}$ & 68 & 120 \\
\hline $\mathbf{T a 2}$ & Contig452 & $\begin{array}{l}\text { TTCACTGTCTATCCATCTCC/ } \\
\text { ATGAGGAAATCACCTGAGAG }\end{array}$ & 207 & 90 \\
\hline EF1- $\alpha$ & Contig474 & $\begin{array}{l}\text { TGCTGTGCTCATTATTGAC/ } \\
\text { GCATCCATCTTGTTGCAG }\end{array}$ & 137 & 95 \\
\hline PP2A2 & Contig1139 & $\begin{array}{l}\text { AATATGGAAATGCCAACGTC/ } \\
\text { GTAAGCAGAAGACCTGACTC }\end{array}$ & 92 & 120 \\
\hline PUB3 & Contig128 & $\begin{array}{l}\text { GATAGAAGTCCTCAGAAGCA/ } \\
\text { CAATAGTGTCTGAGCTTTC }\end{array}$ & 107 & 98 \\
\hline GAPDH & Contig 804 & $\begin{array}{l}\text { TGGTTGATCTCACTGTTAGG/ } \\
\text { AGACTCCTCTTTGATAGCAG }\end{array}$ & 73 & 100 \\
\hline CICLOF & ВАВX01061345.1 & $\begin{array}{l}\text { AGATTAAACCTCCTGATAATGTCC/ } \\
\text { GATTATTTCAGCCGATGTAACAG }\end{array}$ & 119 & 98 \\
\hline UCP & BABX01067133.1 & $\begin{array}{l}\text { CACCCAAATATTAACAGCAACGG/ } \\
\text { TGAAAGCAACACCTTAGATATGG }\end{array}$ & 92 & 95 \\
\hline $\mathbf{T \beta}$ & ВАBX01023750.1 & $\begin{array}{l}\text { AGGTATACAAGATTTGTCACTCTC/ } \\
\text { GTGAGCATCATTCTGTCAGG }\end{array}$ & 105 & 100 \\
\hline Jc-SRG-1 & Jcr4S01575.50 & $\begin{array}{l}\text { TATGTCCGCAAAGAATGTTGTAGC } \\
\text { GTCGCTGCCTCAGCAACTTTCTCAT }\end{array}$ & 180 & 98 \\
\hline Jc-SRG-2 & Jcr4S28136.11 & $\begin{array}{l}\text { CCGATGGACTATTAGGGGATGAA } \\
\text { CGCTGACGTCGAGGCAACAACA }\end{array}$ & 160 & 95 \\
\hline $\begin{array}{l}\text { presence } \\
\text { curve anal } \\
\text { melting cu } \\
\text { amplificati } \\
\text { primers a }\end{array}$ & $\begin{array}{l}\text { single peak i } \\
\text { (Fig.1). The : } \\
\text { erformed afte } \\
\text { howed that al } \\
\text { ied a single }\end{array}$ & $\begin{array}{ll}\text { he melting } & \text { under } \\
\text { ysis on the } & \text { stability va } \\
0 \text { cycles of } & \text { samples. } \\
\text { ne pairs of } & \text { stability ca } \\
\text { R product } & \text { transforme } \\
\text { ecificity of } & \text { delta-Ct m }\end{array}$ & $\begin{array}{l}\text { conditio } \\
\text { ere dete } \\
\text { es were } \\
\text { ns for Be } \\
\text { lative qu } \\
\text { GeNorm, }\end{array}$ & $\begin{array}{l}\text { Expression } \\
\text { ded across all } \\
\text { d directly for } \\
\text { eeper or were } \\
\text { ties using the } \\
\text { rmFinder). }\end{array}$ \\
\hline
\end{tabular}

qPCR (Fig.1). The mean $\mathrm{Ct}$ (average of four

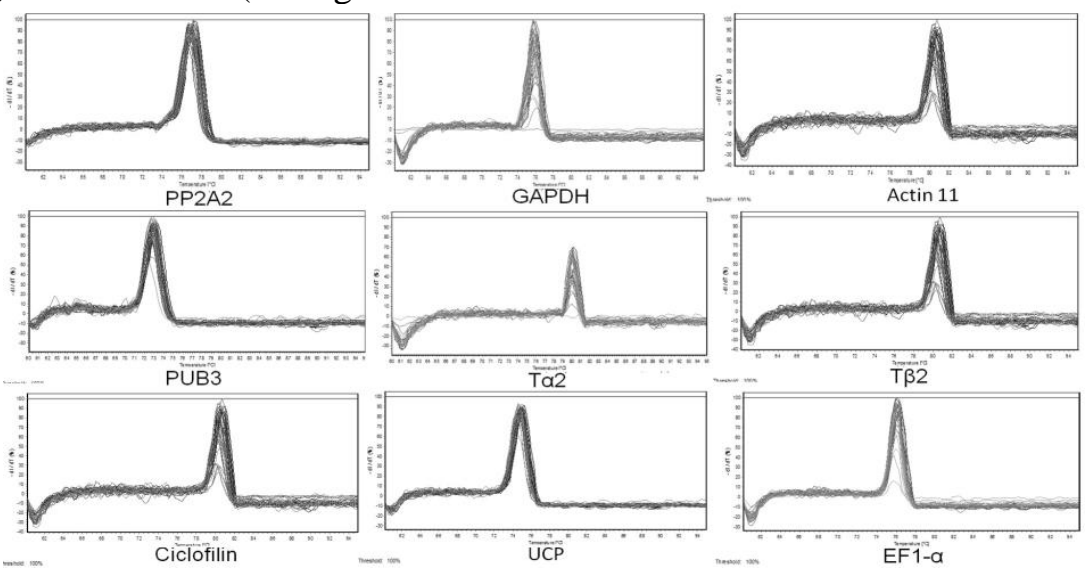

Figure 1-Melting curve of Nine candidate reference genesshowing the specificity of the primers with a single peak: actin-11 (ACT11), tubulin alpha-2 (T $\alpha 2)$, Tubulin beta (T $\beta 2)$, Ciclofilin, Ubiquitin conjugation 
Identification of suitable reference genes for gene expression normalization in Jatropha curcas $L$ during development and under stress conditions using Real Time Quantitative PCR

protein (UCP) elongation factor 1-alpha (EF1- $\alpha$ ), protein phosphatase 2A-2 (PP2A2), polyubiquitin-3 (PUB3) and glyceraldehyde-3-phosphate dehydrogenase (GAPDH).

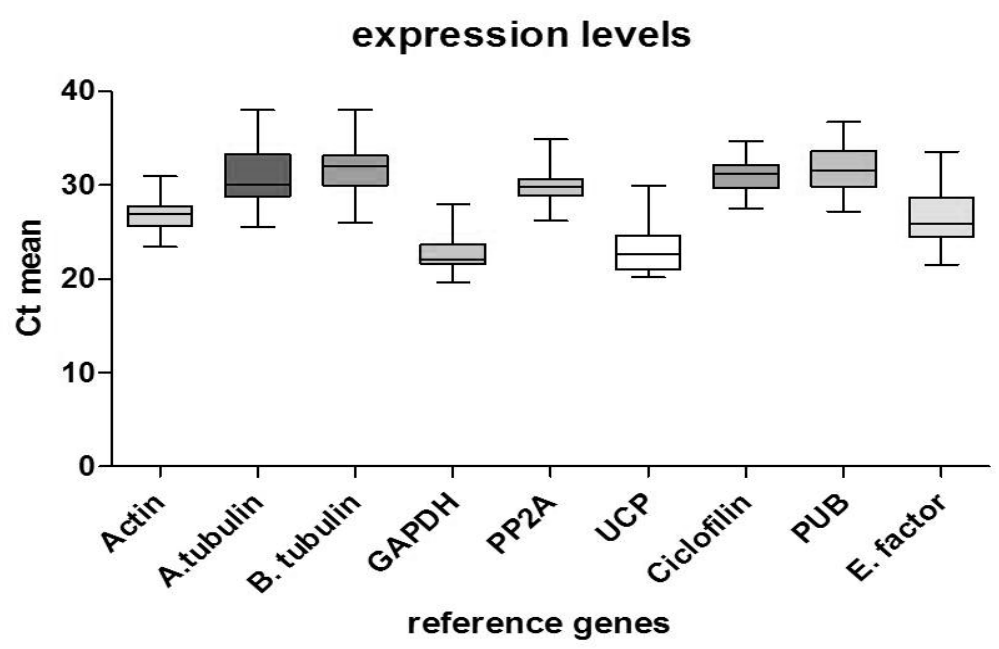

Figure 2-Ranking of the transcript levelsof reference genes, based on the mean $\mathrm{Ct}$ values. The GAPDH and UCP were the most expressed transcripts, whereas PUB and tubulin-beta were the less expressed transcripts.

\section{Stability of the expression of reference genes by qPCR}

Our results showed that GAPDH, UCP with respective $\mathrm{Ct}$ (cycle threshold) means of 22.60 and 23.08 presented the highest transcript levels in q-PCR, whereas PUB and tubulin-beta with respective $\mathrm{Ct}$ means of 31.71 and 31.76 presented lower transcript expression (Fig.2). The data showed that there are different levels of expression of these genes. GAPDH and UCP were little expressed, but were regarded as the best genes, but their stability in each studied tissue did not depend on the high expression levels, as for example PP2A2 with lower expression levels, and GeNorm, BestKeper and NorFinder considered these genes more stable.

\section{GeNorm analysis}

The first experiment used developing seeds collected at 10-15, 20-25, 30-35 days after pollination (DAP) and, with the exception of EF1- $\alpha$ and tubulin alpha-2 (T $\alpha 2)$, all genes expressed cutoff values for $M$ of $<1.0$, as suggested by GeNorm. The most stable reference gene for samples of developing Jatropha curcas seeds were: GAPDH, UCP, ACTIN, PP2A2 and ciclofilin (Fig.3).
However, the less stable genes were: EF1- $\alpha$ and tubulin alpha-2. Under stress conditions, different gene combinations were also necessary for accurate normalization. For total (a mix of all conditions) and SA stress treatments, three and four genes were respectively required to normalize gene expression in leaves (Fig.3). Nevertheless, for PEG and $\mathrm{NaCl}$ stress treatments, four and five genes were respectively necessary to normalize gene expression. These results were observed when all seedlings were exposed to stress at 0, 3, 6 and 12h (Fig.4).

The best combinations of stable genes in each tissue under stress conditions were as follows: for total stress, the following two genes were used for normalisation: E. factor, PP2A and GAPDH.However, in SA stress, four genes were required: PP2A, E. factor, GAPDH and PUB. In PEG stress, two genes were identified as the best genes for normalisation: PP2A and E. factor, while in $\mathrm{NaCl}$ stress, five genes were necessary: PP2A, GAPDH, E. factor, PUB and B. tubulin (Figs. 3, 4) as suggested by geNorm with cutoff values for $\mathrm{M}$ of $<1.0$. 
Rocha, AJ et al.

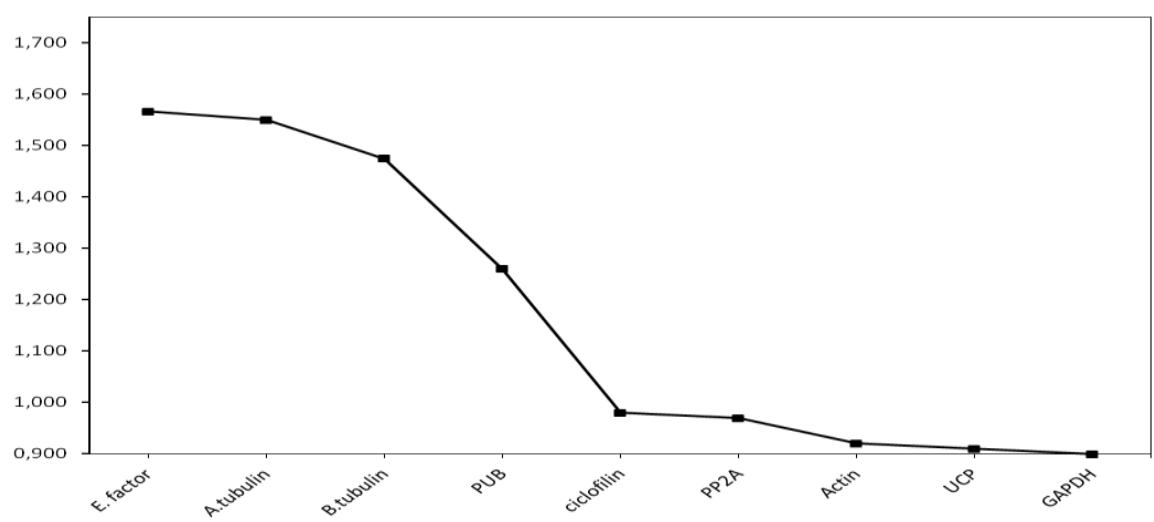

Figure 3-Gene expression stability and ranking of reference genes calculated by geNorm from developing seeds of Jatropha curcas. The lower value of average expression stability indicates more stable expression.

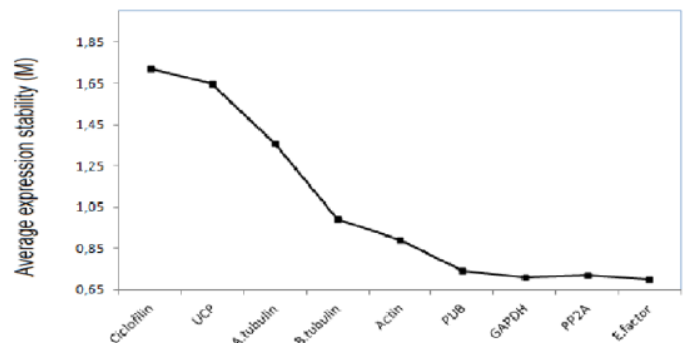

total stress

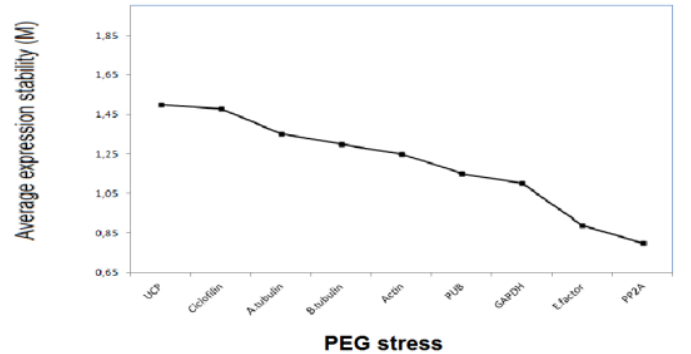

Last stable gene

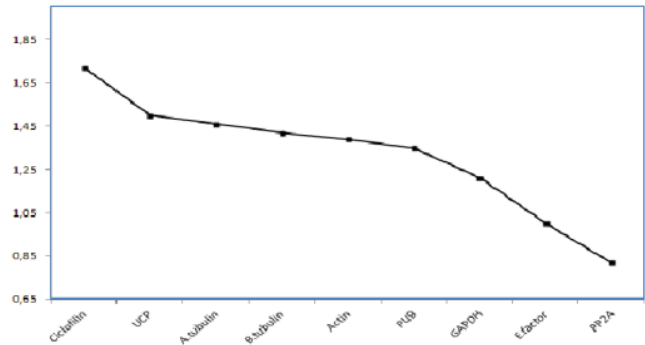

SA stress

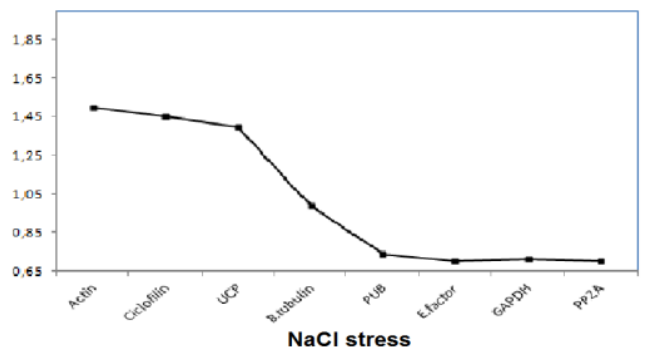

Most stable genes $\longrightarrow$

Figure 4 - a) Gene expression stability and ranking of reference genes calculated by geNorm from developing seeds of Jatropha curcas. The lower value of average expression stability indicates more stable expression.(b) ranking of reference gens reported to geNorm under stress conditions.

\section{NormFinder analysis}

The Normfinder results revealed that when all samples were used, the most stable genes were PP2A,,GAPDH, UCP and ACTIN, with respective stability values of 0.102 , $0.212 ; \quad 0.287$ and 0.301 (Table S1). However, when only developing samples were used, the most stable genes were GAPDH, UCP, PP2A and ciclofilin with respective stable values of $0.035 ; 0.052$;

Therefore, GAPDH; PP2A and EF1- $\alpha$ were identified as the best genes for normalization
0.148 and 0.262 (Table S.1). Moreover, when stress conditions were used in input data, the PP2A, GAPDH, EF1- $\alpha$ were regarded as the most stable genes with stability values in all stress conditions (total, PEG, SA and $\mathrm{NaCl}$ ) (Table S1).

Table S1 in Attachment.

of RT-qPCR data, but not necessarily in the same order. However, when under PEG and 
Identification of suitable reference genes for gene expression normalization in Jatropha curcas $L$ during development and under stress conditions using Real Time Quantitative PCR

$\mathrm{NaCl}$ stresses, GAPDH, EF1- $\alpha$ and PP2A were also the best genes in the same order. These results are in agreement with GeNorm $M$ results that showed PP2A, GAPDH, UCP and ACTIN (development) and PP2A EF1$\alpha$, and GAPDH (stress conditions) as best reference genes for proper data normalization.

\section{BestKeeper analysis}

The BestKeeper revealed that the best correlations were $\mathrm{PP} 2 \mathrm{~A}(\mathrm{r}=0,958 ; \mathrm{SD}=1,38)$; GAPDH $(\mathrm{r}=0,887 ; \mathrm{SD}=1,29)$ and beta tubulin $(\mathrm{r}=0,843 ; \mathrm{SD}=1,02)$ and alpha tubulin $(\mathrm{r}=0,889 ; \mathrm{SD}=1,04)$ respectively, with both p-values of 0,001 (Table S2). Since the Nine candidate reference genesselected for stability expressed SD values below 2, all these genes were indicated for the normalization of qPCR data, as suggested by Pfaffl et al (2004). These results were in agreement with GeNorm, normFinder data, reinforcing that the use of different programs for all the combined data, allowed the selection of the same genes as the best reference genes for the normalization of qPCR data.

Table S2 in Attachment.

Validation of the selected reference genes

To validate the selected reference genes, the relative transcript levelsof two stressresponsive genes of JatrophaJc-SRG-1 and Jc-SRG-2 were evaluated in leaf samples from developing seeds and seedlings under exposure to various stress conditions (total stress, PEG, SA and $\mathrm{NaCl}$ ) in the control (0h), 3, 6 and 12 hours after application of the four stress treatments. Three program were used to identify the most stable genes (GeNorm, NorFinder and BestKeeper), however only the reference genes suggested by GeNorm were used for validation of the qPCR data using the relative gene expression of Jc-SRG-1 and Jc-SRG2(Table s). NorFinder and BestKeeper basically identified the same genes, with changes only in the position of these genes. Hence, in the present experiments only data generated by Genorm were considered and were used to validation using of two target genes (Jc-SRG-1 and Jc-SRG-2)(Table 7). In regarding to geNorm $\mathrm{V}$ value in developing seeds were necessary five genes: GAPDH, UCP, Actin and PP2A (Fig.3) to normalisation of qPCR data suggested by geNorm V (Fig.5). However, with exception of the use of five genes, when to incorporates new gene to gene analysis or withdraws the analysis, the $\mathrm{V}$ values increase to values considerably higher, but still above the cutoff value 0.15 suggest by GeNorm V values (fig.5). In the four stress conditions there are differences in the each condition stress (Fig.6). In leaves exposure to total stress were needed three genes were used to normalisation: E. factor, PP2A and GAPDH; however, in SA stress, four genes were required: PP2A, E. factor, GAPDH and PUB (Figs.4, 6). In PEG stress, were necessary four genes: PP2A, E. factor, GAPDH and PUB. In $\mathrm{NaCl}$ stress, five genes were necessary: PP2A, GAPDH, E. factor, PUB and B. tubulin (Figs.4, 6). Normally, 0.15 has been recommended as a cut-off value for the pair-wise variation, below which the inclusion of additional reference genes is not required, although this should not be an absolute rule 
Rocha, AJ et al.

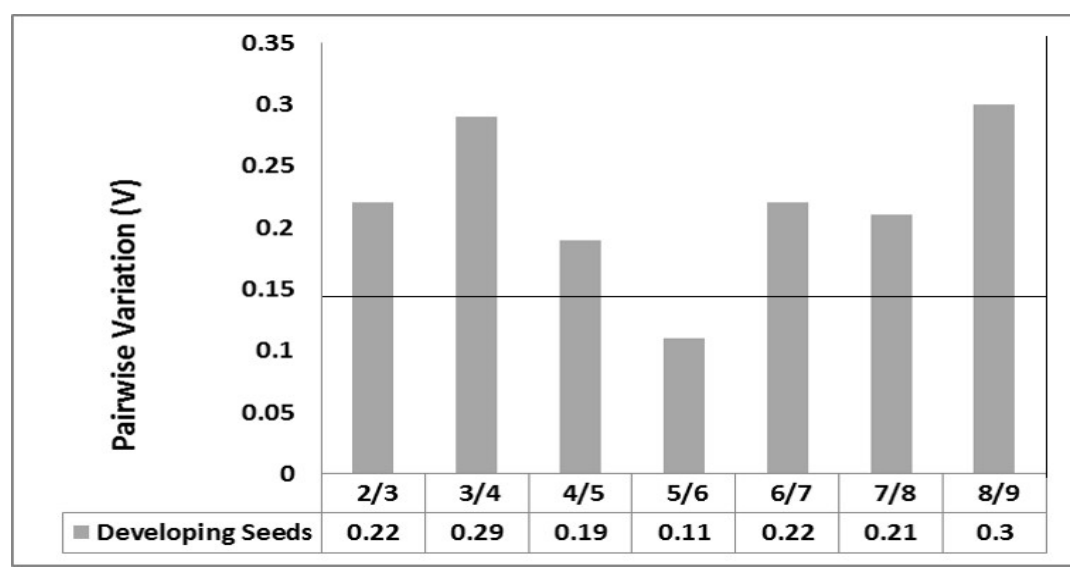

Figure 5- Determination of the optimal number of reference genes. The geNorm $\mathrm{V}$ suggest the number of 5 reference genes for normalisation of developing samples in J. curcas seeds.

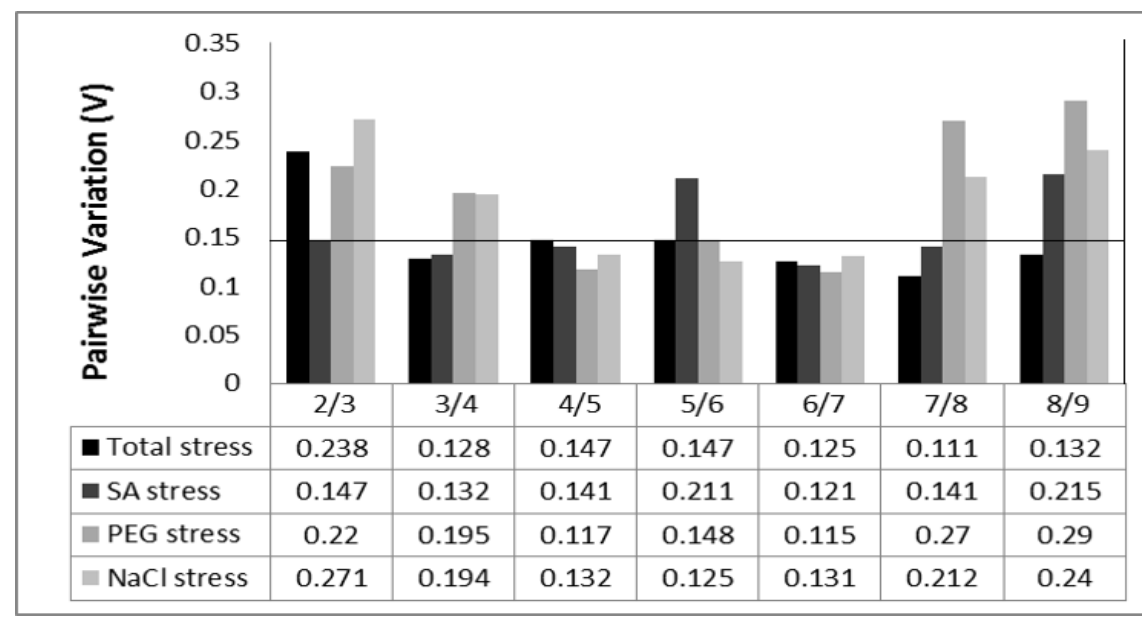

Figure 6- Determination of the optimal number of reference genes. The geNorm $\mathrm{V}$ suggest the number of 5 reference genes for normalisation of samples in stress conditions in leaves of J. curcas.

In relation to developing seeds, gene expression of Jc-SRG-1 showed a gradual increase, from 0 days throughout seed maturation (Figure S3). However, the levels of expression of Jc-SRG-2 gene achieved a gradual increase up to around 20-25 days after pollination(DAP), and the levels of expression decreased around 30-35 days and returned to full growth in mature seeds (Figure S3).

Leaves of Jatropha curcas submitted to four different stress conditions (total, PEG, SA and $\mathrm{NaCl}$ ) showed a differential expression of the Jc-SRG-1 gene under each individual stress condition and all stress conditions combined. In the presence of total stress condition a gradual increase of the transcript levelsof the Jc-SRG-1 gene was observed until up to $6 \mathrm{~h}$ of stress, transcript levelsdecreased after $12 \mathrm{~h}$ under all stress conditions (Figure S3). Similar expression patterns of the Jc-SRG-1 gene were observed under PEG and total stress conditions; however, total stress conditions rendered higher transcript levelsin comparison to stress conditions following treatment with PEG (Figure S3). Stress conditions generated by $\mathrm{SA}$ and $\mathrm{NaCl}$ resulted in very similartranscript levelsof the Jc-SRG-1 gene, but $6 \mathrm{~h}$ of $\mathrm{NaCl}$ stress resulted in transcript levelstwice as high as the ones observed following $6 \mathrm{~h}$ under SA stress (Figure S3).

Jc-SRG-2gene transcript levelssignificantly surpassed the expression of Jc-SRG1.Transcript levelsof the Jc-SRG-2 gene under total stress conditions started with a gradual increase at $3 \mathrm{~h}$ and lasted until up to 12h (Figure S3). In the PEG stress conditions, an increased expression of the 
Identification of suitable reference genes for gene expression normalization in Jatropha curcas $L$ during development and under stress conditions using Real Time Quantitative PCR

Jc-SRG-1 gene was initially observed at $3 \mathrm{~h}$ and increased abruptly after $6 \mathrm{~h}$ and $12 \mathrm{~h}$ of stress (Figure S3). Stress conditions generated by $\mathrm{SA}$ and $\mathrm{NaCl}$ resulted in high levels of Jc-SRG-2 gene expression,

\section{DISCUSSION}

The present study selected and studied $J$. curcas in differentdevelopmental stages andunder various stress conditions. In addition, nine candidate reference genes and three softwares (geNorm, BestKeeper and NormFinder)were used to provide information on gene expression stability. In addition, seedlings were subjected tofour different stress conditions, which included total stress,SA, PEG and $\mathrm{NaCl}$. Zhang et al. (2013) published a study aiming to select the best reference genes in J.curcas, using different parts of this plant under two different stress conditions: desiccation and cold treatments.

Zhang et al. (2013) recommended the use of reference genes GAPDH and EF1 $\alpha$ for normalisation in qPCR assay in the reproductive stage. These results are in agreement with our work. Furthermore, for abiotic stress treatments, they recommended the use of TUB5 and TUB8 genes for normalization under desiccation stress, as well as, GAPDH and actin for normalization under cold stress. These findings are in agreement with our data, except the PP2A2 and EF1 $\alpha$ that were considered the best reference genes in our work. In general, in our study GAPDH and PP2A2 were considered the best reference genes in almost all the studied conditions.

In regards to the experimental design, Zhang et al. (2013) used vegetative stage tissues (roots, hypocotyl, cotyledons, young leaves, and mature leaves), but the authors were not careful enough in selecting each stage of time of these tissues for the study. In the present work samples were collected at 10-15, 20-25, 30-35 days after pollination (DAP) and maturation of seeds, increasing the condition of analysis on developing seeds ofJatropha curcas, because the time however, $6 \mathrm{~h}$ of $\mathrm{NaCl}$ stress revealed higher levels of this gene than $6 \mathrm{~h}$ of SA stress (Figure S3).

Figure S3 in Attachment.

selected for each tissue is very importante for the linear quantitative expression increasing and/or decreasing in both reference and target genes. Furthermore, we studied four stress conditions (PEG, SA, $\mathrm{NaCl}$ and a mix of all 3 conditions) after 0 ; 3 ; 6 and 12 hours of exposure to these conditions. Zhang et al. (2013) restricted their experiments to only 2 stress conditions (desiccation and cold treatments). Therefore, in this context, the present study constitutes an in-depth normalization study using reference genes of the Jatropha curcas, being the present work more careful in the experimental point of view, and more complete in comparison to two previous studies (Rocha et al. 2013 and Zhang et al. 2013).

Ribeiro et al. 2014 also attempted to identify stably expressed genes, and thus potential reference genes to apply in Ricinus communis, providing important guidelines for qPCR studies in seeds and seedlings for other species.GeNorm and NormFinder indicated that ACT, POB and PP2AA1 as the optimal combination for normalization of gene expression data in inter-tissue (heterogeneous sample panel) studies. In general, the most stable genes suggested by GeNorm were very consistent with those indicated by NormFinder, which highlighted the strength of the selection of reference genes,agreeing with our study, since PP2AA and actin 11 werealso regarded one of the best reference genes in our study.

Based on data gathered from GeNorm, these candidate reference genes were suggested as beingappropriate and reliable for normalization data inJ.curcas.In spite of the stability of these reference genes,candidate reference genesunderstress conditionsmay demonstrate significant variations in stability that must be considered, for example, the reference genes EF1- $\alpha$ and PUB were regardedas stable under various

Braz. Arch. Biol. Technol. v.59: e0396, Jan/Dec 2016 
Rocha, AJ et al.

stress conditions, but in development seeds were not appropriate for normalization data (Figs.3, 4). Nevertheless, the Tubulin $\beta 2$ gene showedlessstability in development seedsand under stress conditions (Figs.3, 4). These findingssuggest that stability may vary according totissue typeand experimental conditions; hence, a candidate reference gene may be more stable ina given tissue or less reliable on a differentone.

In our study, GAPDH and PP2A were regarded as the best candidate genes, and EF1-awas more stable understress conditions than developing seeds. These genes (GAPDH, PP2A and EF1- $\alpha$ ) were used for normalisation inexperimental studies with citrus fruits (Niu et al. 2011), Coffea Arabica (Cavalari et al. 2009)andcoffee (Barsalobres-Cavallari et al. 2009. Furthermore, GAPDH and PP2A have been used as reference genes in tissuespecific and genotype-variable gene expression in sugarcane (Saccharum sp) (Iskandar et al. 2004). To validate our study, we studied the expression pattern of the response-stress genes: Jc-SRG-1 and JcSRG-12 were annotated and used this study. These genes were employed for normalisation using the best reference genes suggested by the GeNorm. Each stress condition showed different expression patternsof these genes. Notoriously, the levels of gene expression of Jc-SRG-2 were higher than Jc-SRG-1under all stress conditions, mainly of leaves under exposure to 3-12h on PEG and $\mathrm{NaCl}$ stress. The transcript levels of Jc-SRG-2 seemed to be more correlated with stress responses than changes in transcript levels of Jc-SRG-1 (Figure S3).

The present studyshowed robust results, and revealed the best reference genes suggested by the GeNorm, NormFinder and BestKeeper to obtain reliable results for qPCR normalization. It should be pointed out that transcriptomes could differ considerably among specific seed tissues.This fact has been shown in soybean (Le et al. 2007, Saraiva et al, 2014), barley (Barrero et al. 2009), Arabidopsis (Le et al. 2010). Therefore, the stably expressed genes validated in this study in tissues of developing seedlings and under various stress conditions can be used in future studiesunder the same employed conditions. These resultscannot be applied to specific seed tissues, such as embryo and nucellus. Moreover, these genes should not be widely used under conditions other than the ones tested in the present study, such as stratification, cold and heat stress conditions. In these cases, the use of multiple reference genes across the experiment or the reevaluation of novel reference genes are recommended strategies (Rocha et al. 2015). In conclusion, different tissues or experimental conditions requirespecific reference genes.

\section{CONCLUSION}

In this study, comparison of the results acquired from the geNorm, Normfinder and Bestkeeper software applications indicated GAPDH, PP2A as best reference genes for data normalization in qPCR assay among nine candidate genes of developing seeds and leaves of $\mathbf{J}$. curcas seedlings, under specific stress conditions. Furthermore, transcript levels of Jc-SRG-2 seemed to be more correlated with stress responses than changes in transcript levels of Jc-SRG1.Taken together, GAPDH and PP2A2 revealed an important role of these two genes. Therefore, this study provided guidelines for selecting the best reference genes in Jatropha curcas seeds, and in tissues submitted to different stress conditions.

\section{ACKNOWLEDGEMENTS}

We are grateful for the financial assistance fromthe $\mathrm{CNPq}$, CAPES, Universidade Federal de Pelotas-UFPeland Universidade Federal do Ceará-UFC.

\section{REFERENCES}

AndersenCL, Orntoft TF. (2004). Normalization of real-time quantitative reverse transcriptionPCR data: A model-based variance estimation approach to identify genes suited for normalization, applied to bladder and colon cancer data sets. Cancer Res. 2004; 64: 52455250 . 
Identification of suitable reference genes for gene expression normalization in Jatropha curcas $L$ during development and under stress conditions using Real Time Quantitative PCR

Asif MH, Mantri SS, Sharma A, Srivastava A, Trivedi I, Gupta P, et al. Complete Sequence and organization of the Jatropha curcas (Euphorbiaceae) chloroplast genome. Tree Genetics \& Genomes. 2010;6: 941-952.

Barrero JM, Talbot MJ, White RG, Jacobsen JV, Gubler F. Anatomical and transcriptomic studies of the coleorhiza reveal the importance of this tissue in regulating dormancy in barley. Plant Physiol. 2009;150: 1006-1021.

Barsalobres-CavallariCF, Severino FE, Maluf MP, Maia IG.Identification of suitable internal control genes for expression studies in Coffea arabica under different experimental conditions, BMC Molecular Biology. 2009; 10:1.

Chervoneva I, Li Y, Schulz S, Croker S, Wilson C, Waldman SA, Hyslop T. Selection of optimal reference genes for normalization in quantitative RT-PCR. BMC Bioinformatics. 201011: 253.

Cordoba EM, Die JV, Gonza'lez-Verdejo CI, Nadal S, Román B. Selection of reference genes in Hedysarum coronarium under carious stresses and stages of development. Anal Biochem Mol Biol Rep. 2011; 409: 236-243.

Costa GGL, Cardoso KC, Del Bem LEV, Lima AC, Cunha MAS, Campos-Leite L, Vicentini R., Papes F, Moreira RC, Yunes JA, Campos FAP, Da Silva M.J.Transcriptome analysis of the oil-rich seed of the bioenergy crop Jatropha curcas L. BMC Genomics .2010, 11: 462.

Harada JJ, Goldberg RB. Global analysis of gene activity during Arabidopsis seed development and identification of seed-specific transcription factors. Proc Natl Acad Sci2010; 107: 80638070

Iskandar HM, Simpson RS, Casu RE, Bonnett GD, Maclean DJ, Manners JM. Comparison of Reference Genes for Quantitative Real-Time Polymerase Chain Reaction Analysis of Gene Expression in Sugarcane. Plant Mol Biol Rep. 2004; 22: 325-337.

Soares, Emanoella L. ; Shah, Mohibullah ; Soares, Arlete A. ; COSTA, JOSÉ H. ; CARVALHO, PAULO ; Domont, Gilberto B. ; Nogueira, Fábio C. S. ; Campos, Francisco A. P. . Proteome Analysis of the Inner Integument from Developing Jatropha curcas L. Seeds. Journal of Proteome Research (Print), v. 13, p. $140722072759001,2014$.

Shah, Mohibullah ; SOARES, EMANOELLA LIMA ; CARVALHO, PAULO C. ; SOARES, Arlete Aparecida ; Domont, Gilberto B. ; Nogueira, Fabio C.S. ; Campos, Francisco A.P. - Proteomic Analysis of the Endosperm
Ontogeny of Jatropha curcas L. Seeds. Journal of Proteome Research (Print), v. 4, p. $150429033634001,2015$.

Le BH, WagmaisterJA, Kawashima T, Bui AQ, Harada JJ, Goldberg RB.Using genomics to study legume seed development. Plant Physiol. 2007; 144: 562-574.

Marshall J. PerlPrimer: cross-platform, graphical primer design for standard, bisulphite and realtime PCR. Bioinformatics. 2004; 20(15): 24712472.

Natarajan P, Kanagasabapathy D, Gunadayalan G, Panchalingam J, Shree N, Sugantham PA.Gene discovery from Jatropha curcas by sequencing of ESTs from normalized and fulllength enriched Cdna from developing seeds. BMC Genomics. 2010;11: 606.

Niu JZ, Dou W, Ding TB, Yang LH, Shen GM, Wang JJ. Evaluation of suitable reference genes for quantitative RT-PCR during development and abiotic stress in Panonychus citri (McGregor)(Acari: Tetranychidae). Mol Biol Rep. 2012; 39(5): 5841-9.

Paolacci AR, Tanzarella OA, Porceddu E, Ciaffi $M$. Identification and validation of reference genes for quantitative RT-PCR normalization in wheat. BMC Mol Biol. 2009; 10:11.

Pfaffl MV, TichopadA, Prgomet C, Neuvians TP. Determination of stable housekeeping genes, differentially regulated target genes and sample integrity: BestKeeper- Excel-based tool using pair-wise correlations. Biotechnology Letters. 2004; 26: 509-515.

Rocha, AJ, Monteiro-Júnior, JE, Freire, JEC, Sousa AJS, Fonteles CSR . Real Time PCR: the Use of Reference Genes and Essential Rules Required to Obtain Normalisation Data Reliable to Quantitative Gene Expression. Journal of Molecular Biology Research, 2015; 5: 45-55.

Rocha AJ, Soares EM, Costa JH, Costa WLG, Soares AA, Nogueira CS, Domont GB, Campos FAP. Differential expression of cysteine peptidase genes in the inner integument and endosperm of developing seeds of Jatropha curcas L. (Euphorbiaceae), Plant Science. 2013; 213: 30-37.

Rocha, AJ, Miranda RS, Cunha RMS. Assessment of DNA Polymerases in microsatellite amplification assays through PowerPlex 16 BIO System. BBR Biochemistry and Biotechnology Reports, 2014.(DOI:10.5433/2316-5200.2014v3n2p1).

Ribeiro PR, Dekkers, BWJ, Fernandez, LG, De Castro, R.D., Ligterink, W, Hilhorst HWM. (2014). Identification of reference genes for 
Rocha, AJ et al.

gene expression studies during seed germination and seedling establishment in Ricinus communis L. Seed Science Research, 2014; 4: $341-352$.

Sambrook J, Fritsch EF, Maniatis T. Molecular cloning: a laboratory manual. Cold Spring Harb Lab Press, New York, 1989.

Sato S, Hirakawa H, Sachiko I, Hirakawa H, Isobe $\mathrm{S}$, Fukai $\mathrm{E}$, Watanabe $\mathrm{A}$, Kato $\mathrm{M}$, Kawashima K.,et al. Sequence analysis of genome of an Oil-bearing tree, Jatrophacurcas L.DNA Research2001; 1: 12.

Saraiva KDC, Melo DF, Morais VD, Vasconcelos IM, Costa JH. Selection of suitable soybean EF1a genes as internal controls for real-time PCR analyses of tissues during plant development and under stress conditions. Plant Cell Reports, 2014; 33: 14531465.
Vandesompele J, De Preter K, Pattyn F, Poppe B, Van Roy N, De Paepe A, Speleman, F.Accurate normalization of real-time quantitative RTPCR data by geometric averaging of multiple control genes. Genome Biol. 2002;3(7): research0034.1-0034.11.

Zhang L, He L, Fu QT, Xu Z.F.Selection of Reliable Reference Genes for Gene Expression Studies in the Biofuel Plant Jatropha curcasUsing Real-Time Quantitative PCR. Int. J. Mol. Sci 2013;14: 24338-24354.

Received: July 07, 2015;

Accepted: January 11, 2015. 